\title{
Nucleolar size in lymphocytes and haemocytes of different species
}

\section{J. Berger}

Faculty of Health and Social Studies, University of South Bohemia, Ceske Budejovice, Czech Republic

\section{(C2008 European Journal of Histochemistry}

The number of nucleoli in a cell and nucleolar area vary according to the cell. We compared nucleoli in mammalian circulating lymphocytes and insect circulating haemocytes. An increased nucleolar coefficient correlated with a lowered nucleoli size. The smaller nucleolar size in mammalian lymphocytes indicates a lower proteosynthetic cellular activity in both mammalian lymphocytes and insect haemocytes. Moreover, in insect haemocytes, the smaller size of the nucleoli may reflect a lowered potential to transform into another cell type.

Key words: nucleolus, size, coefficient, mononuclear development.

Correspondence: Josef Berger,

Faculty of Health and Social Studies, University of South Bohemia, Emy Destinove, 37005 Ceske Budejovice, Czech Republic

Tel.: +420.3.89037401.

Fax: +420.3 .85787589 .

E-mail: berger@jcu.cz

Paper accepted on June 12, 2008

European Journal of Histochemistry

2008; vol. 52 issue 3 (July-September): 149-152
$\mathrm{T}$ he nucleolar structure may be considered as a morphological expression of its functional activity related to the production of preribosomal ribonucleic acids. The size of the nucleoli can vary under various physiological or pathological conditions (Derenzini et al., 2000; Pébusque and Seïte, 1981; Medina et al., 2000; Canet et al., 2001; Smetana, 2002; Berger and Berger, 2004; Biggiogera et al., 2004; Berger et al., 2005; Giuffrè et al., 2006; Hozak and Fakan, 2006; Sirr et al., 2007).

The mean number of nucleoli per human cell - i.e., nucleolar coefficient - is very stable with respect to the cell type. This coefficient is lower in the early stages of granulopoietic precursors and blasts (Smetana et al., 2002).

There are no publications on the comparison of nucleolar size in blood cells in different species. Both vertebrate blood cells and invertebrate haemocytes seem to be evolutionally conserved cells (cf. Hartenstein, 2006) and, therefore, we compared them. As mammalian granulocytes are subject to a programme of cell death and have no nucleoli, we examined circulating lymphocytes, which are also morphologically similar to invertebrate haemocytes.

We selected five species, which are important in biomedical research and practice. Nucleoli in human lymphocytes are studied on the grounds of their frequent significance in biomedicine (Smetana et al., 1997). Mouse and rat lymphocytes have been chosen because these animals serve as an important biomodel in preclinical studies (Berger, 1987). Egyptian cotton leafworm and linen bug haemocytes would be a useful model in insect toxicology (Gelbic et al., 2006; Berger and Slavickova, 2008). Both cell types examined, i.e., lymphocytes and haemocytes, represent circulating and immunocompetent cells. The first type of cell may de-differentiate and the transformation of the second type to other cell types cannot be ruled out. We show that mononuclear nucleolar size depends on species and we discuss this finding in the framework of cell physiology. 


\section{Materials and Methods}

Human subjects were between 18 and 50 years old, Wistar rats were 8 weeks old, W:Han mice were 8 weeks old, Egyptian cotton leafworms Spodoptera littoralis were in the 6th (last) instar, and the linden bugs Pyrrhocoris apterus were adult. Rats and mice were under controlled lightdark cycle 12:12h (switch on 6:00), temperature $22^{\circ} \mathrm{C}$, humidity $65 \%$. Cotton leafworms and inden bugs were under light-dark cycle 16:8h (switch on 6:00), temperature $24^{\circ} \mathrm{C}$, and humidity $65 \%$.

Smears of both peripheral blood and haemolymph were stained for RNA with buffered toluidine blue at $\mathrm{pH} 5$ (the McIlvain buffer) without previous fixation in order to visualise the morphology of the nucleoli (Smetana et al., 1969). Samples of blood were taken at 7:008:00 and that of haemolymph at 10:00-10:30 to prevent the influence of circadian rhythms (Berger and Berger, 2004).

We made photos of mammalian lymphocytes and insect haemocytes using a Nikon Eclipse 50i, Plan oil objective 100x/1.25 and CCD camera Nikon DR-5M. We measured a nucleolar area of at least 50 cells per one human subject or animal using Nikon Imaging Software, Elements Advanced Research, ver 2.30. We also examined the nucleolar coefficient as the mean number of nucleoli per cell.

Data are expressed as mean \pm s.e.m. The results were processed by the two-side Mann-Whitney $\mathrm{U}$ test at the significance level $2 \alpha=0.05$.

\section{Results and Discussion}

The results are shown in Table 1 , and nucleoli in the nominated cell types of the examined species are documented in Figure 1. Human lymphocyte nucleoli are larger than those studied in laboratory rodents. The nucleoli size in linden bug haemocytes is similar to rodent lymphocytes, but their nucleolar coefficient is significantly higher. Leafworm haemocyte nucleoli were the smallest: $0.40 \pm 0.02 \mu \mathrm{m}^{2}$ in panoptically stained smears. Human lymphocyte nucleoli were the largest: $1.55 \pm 0.12 \mu \mathrm{m}^{2}$.

Rodent lymphocytes contain a higher number of nucleoli than human lymphocytes. Egyptian cotton leafworm contains the highest number of haemocyte nucleoli; their nucleolar coefficient was twice as high as that in mammalian lymphocytes. The correlation between nucleolar coefficient and size was negative: the correlation coefficient is -0.893 (statistically significant; $r_{p}=0.811$ at $p=0.05$ ). No biologically significant difference between mammalian males and females was found; the sex of the insects was not detected.

The nucleolar coefficients of human lymphocytes we observed are similar to the data obtained by Potmesil and Wienerova (1965). The nucleolar size of human lymphocytes was larger in our study than the values published previously by Raška and Smetana (1978). This difference may be a consequence of the fact that we used a quite different method of nucleolar size determination and that we investigated a higher number of cells. Our observation of the absence of a sex influence in the mammalian cell types examined confirms previous

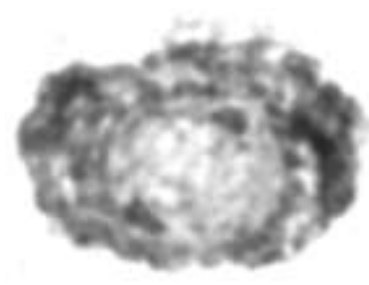

A

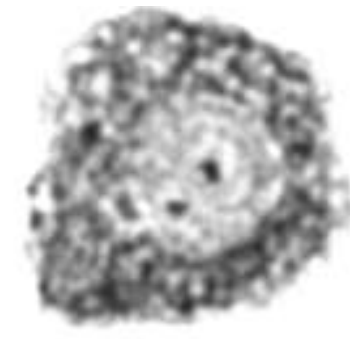

B

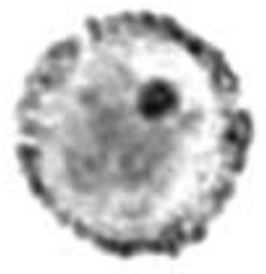

C

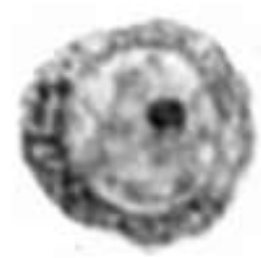

D

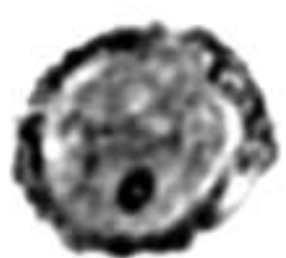

E

Figure 1. Nucleoli in toluidine blue stained circulating mononuclears. A, Pyrrhocoris apterus haemocyte; B, Spodoptera litoralis haemocyte; C, mouse lymphocyte; D, rat lymphocyte; E, human lymphocyte. 
Table 1. Nucleolar size and coefficient in mammalian lymphocytes and insect haemocytes.

\begin{tabular}{lllll}
\hline Species & $\begin{array}{l}\text { Area } \\
\left(\mu m^{2}\right)\end{array}$ & $\begin{array}{l}\text { Nucleolar } \\
\text { coefficients }\end{array}$ & $\begin{array}{l}\text { Number of } \\
\text { nucleoli }\end{array}$ & $\begin{array}{l}\text { Number of } \\
\text { subjects or } \\
\text { animals }\end{array}$ \\
\hline Human subjects & $1.55 \pm 0.12^{*}$ & $1.10 \pm 0.05$ & 1200 & 20 \\
Rat & $1.21 \pm 0.10^{*}$ & $1.31 \pm 0.06^{*}$ & 1000 & 15 \\
Mouse & $1.14 \pm 0.11^{*}$ & $1.33 \pm 0.07^{*}$ & 750 & 15 \\
Linden bug & $1.12 \pm 0.16^{*}$ & $1.89 \pm 0.05^{*}$ & 550 & 12 \\
Cotton leafworm & $0.40 \pm 0.02^{*}$ & $2.23 \pm 0.07^{*}$ & 2200 & 60 \\
\hline
\end{tabular}

${ }^{\S}$ numbers of nucleoli per one cell; ' ${ }^{2}$ mean \pm s.e.m.; * statistically significant as compared with human subjects ( $U$ test, $2 \alpha=0.05$ ).

observation (Smetana et al. 1997) in human monocyte nucleoli.

Large nucleoli have been described in various human haematopoietic cells with one nucleolus while different cells of the same lineage with higher nucleolar coefficient have been found to have multiple nucleoli (Wickenhauser et al., 1995; Cerruto et al., 2006). Mammalian haematopoietic stem cells have a morphology similar to lymphoid cells (Rubinste and Trobaugh, 1973; Wickenhauser et al., 1995). Neverheless, the concentration of circulating haemopoietic stem cells among circulating lymphocytes is very low, so it can be used as an indicator of the differentiation potential of the cell. Human lymphocytes are cells expecting some stimuli to activate proteosynthesis during the immune reaction (Šrámková and Fofitová, 1972; Xu and Shi, 2007, for review).

In contrast, insect circulating haemocytes are partly immature cells that easily transform into another haemocyte type (Lavine and Strand, 2002; Ling et al., 2005, for review). The larger nucleoli in haemocytes reflect a higher proteosynthetc activity and may be an indicator of metabolic potential for differentiation similar to mammalian stem cells. This hypothesis supports our finding that $60 \%$ of linden bug prohaemocytes, $30 \%$ of granulocytes and $38 \%$ of plasmatocytes have compact, i.e. very active, nucleloli, compared to only $5-6 \%$ of rat, mouse and human lymphocytes. Prohaemocytes with a morphology close to mammalian lymphocytes could be candidates for precursors of insect circulating haemocytes.

The highest nucleolar coefficient and the smallest size of nucleoli in leafworm haemocytes are not in accord with the hypothesis of circulating haemocyte transformation into various types. Human mature blood monocytes also have a nucleolar coefficient higher (2.6; Smetana et al., 1997) than blood lymphocytes measured in the data presented here (1.1). Inactive micronucleoli, which are frequent in monocytes, are characteristic of the advanced maturation stages of blood cells. Ringshaped nucleoli, which are reversibly inactive, are very rare in blood monocytes - less than $2 \%$ (Smetana et al., 1997) - although they are usual in almost $90 \%$ of human lymphocytes (Smetana and Potmesil, 1970; Berger and Berger, 2004). The decrease in nucleolar area was also described by Bregnard and Ruch (1974) during cell differentiation in the root cells of Vicia faba and by Altmann (1985) in matured epithelial intestine cells.

As the nucleolar coefficient can be higher in mature cells with a smaller size of nucleloli, leafworm haemocytes seem to be rather close to the physiology of mammalian monocytes. Transformation of the haemocytes of this species seems to be localized rather in haemopoietic tissue and the circulating haemocytes released are differentiated and matured as in mammalian blood cells.

In summary, the smaller nucleolar size in mammalian lymphocytes indicates a lower proteosynthetic cellular activity as well as in insect haemocytes. In insect haemocytes, smaller nucleoli may reflect, moreover, a lower potential for the transformation into another cell type.

\section{References}

Altmann GG. A gradual decrease in nucleolar size with the maturation of columnar epithelial cells in the adult rat intestine under normal and various experimental conditions. J Cell Sci 1985;77:289-304.

Berger J. Haematological preclinical recording of adverse drug reactions - current status, problems, and needs. Part I. Standardization of experiments in relation to haematological examination. Fol haematol 1987;114:1-15.

Berger Z, Berger J. Circadian rhythm of lymphocyte nucleolar area. Comp clin Pathol 2004;12:187-90.

Berger J, Machackova M, Berger Z. Effects of feed restriction on the nucleolar structure and function in lymphocytes. Basic Clin Pharmacol Toxicol 2005;97:236-7.

Berger J, Slavickova K. Morphological characterisation and of the hemocytes in the adult linden bug, Pyrrhocoris apterus (L.) (Heteroptera), Stud Zool 2008; (in press).

Biggiogera M, Bottone MG, Scovassi AI, Soldani C, Vecchio L, Pellicciari C. Rearrangement of nuclear ribonucleoprotein (RNP)containing structures during apoptosis and transcriptional arrest. Biol Cell 2004; 96:603-15.

Bregnard A, Ruch F. Relation between the nuclei and the nucleoli during cell differentiation in roots of Vicia faba volumetric and cytochemical analysis. Histochem Cell Biol 1974;42:247-56. 
Canet V, Montmasson M-P, Usson Y, Giroud F, Brugal G. Correlation between silver-stained nucleolar organizer region area and cell cycle time. Cytometry 2001;43:110-6.

Cerruto CA, Brun EA, Chang D, Sugarbaker PH. Prognostic significance of histomorphologic parameters in diffuse malignant peritoneal mesothelioma. Arch Pathol Lab Med 2006; 130:1654-61.

Derenzini M, Trerè D, Pession A, Govoni M, Sirri V, Chieco P. Nucleolar size indicates the rapidity of cell proliferation in cancer tissues. J Pathol 2000;191:181-6.

Gelbic I,. Strbackova J, Berger J. Influence of metyrapone on the morphology of hemocytes of the Egyptian cotton leafworm Spodoptera littoralis (Boisd). Zool Stud 2006;15:371-7.

Giuffrè G, Mormandi F, Barresi V, Bordi C, Tuccari G, Barresi G. Quantity of AgNORs in gastric endocrine carcinoid tumours as a potential prognostic tool. Eur J Histochem 2006;50:45-50.

Hartenstein V. Blood cells and blood cell development in the animal kingdom. Annu Rev Cell Dev Biol 2006;22:677-712.

Hozák P, Fakan S. Functional structure of the cell nucleus. Histochem Cell Biol 2006; 125:1-2.

Ling E, Shirai K, Kanekatsu R, Kiguchi K. Hemocyte differentiation in the hematopoietic organs of the silkworm, Bombyx mori: prohemocytes have the function of phagocytosis. Cell Tisue Res 2005; 320:535-43.

Medina FJ, Cerdido A, de Carcer G. The functional organization of the nucleolus in proliferating plant cells. Eur $\mathrm{J}$ Histochem 2000;44:117-31.

Pébusque MJ, Seïte. Electron microscopic studies of silver-stained proteins in nucleolar organizer regions: location in nucleoli of rat sympathetic neurons during light and dark periods. J Cell Sci 1981;51:85-94.

Potmesil M, Wienerova E. The nucleolar coefficient of lymphocytes in the peripheral blood of healthy subjects. Folia Morphol 1965; 13:352-61.
Raška I, Smetana K. A further contribution on nucleoli of human lymphocytes. Fol haematol 1978;105:200-15.

Rubinste AS, Trobaugh FE. Ultrastructure of presumptive hematopoietic stem cells. Blood 1973;42:61-80.

Sirri V, Urcuqui-Inchima $S$, Roussel $P$, Hernandez-Verdun D. Nucleolus: the fascinating nuclear body. Histochem Cell Biol 2008; 129:13-31.

Smetana K, Potmesil M. A further contribution on the incidence of ring shaped nucleoli and micronucleoli in mature human lymphocytes. Folia Haematol 1970; 93:16-23.

Smetana K. Structural features of nucleoli in blood, leukemic, lymphoma and myeloma cells. Eur J Histochem 2002;46:125-132.

Smetana K, Lejnar J, Potmesil M. A further contribution to the demonstration of RNA and nucleoli in blood cells in smear preparations. Folia Haematol 1969;91:381-4.

Smetana K, Jirásková I, Turek P, Chan PK, Busch H. A contribution to the incidence of nucleoli in normal human blood monocytes. Haematologia 1997;82:138-42.

Smetana K, Jirásková I, Malasková V,Cermák J. A cytochemical note on nucleoli of granulocytic precursors and granulocytes in patients suffering from the refractory anemia with excess blasts (RAEB) of the myelodysplastic syndrome (MDS). Neoplasma 2002;49:5-9.

Šrámková L, Fortová D. Investigation of lymphocytes activation in peripheral blood in infectious diseases. Z Immunitatsforsch Exp Klin Immunol 1972; 144:129-39.

Wickenhauser $\mathrm{C}$, Thiele J, Kümmel T, Fischer R. Die hämatopoietische Stammzelle des Menschen Funktion und Morphologie. Pathologie 1995;16:1-10.

Xu GW, Shi YF. Apoptosis signaling pathways and lymphocyte homeostasis. Cell Res 2007;17:759-71. 